\title{
Clinical Reasoning: A 54-year-old woman with confusion and visual disturbances
}

Kyle C. Rossi, MD, Rachel Brandstadter, MD, Madeline C. Fields, MD, Jennifer Leong, MD, and Susan Shin, MD Neurology ${ }^{\circledR}$ 2018;91:363-367. doi:10.1212/WNL.0000000000006045
Correspondence

Dr. Rossi

Rossi.KyleC@gmail.com

\section{Section 1}

A 54-year-old woman presented to the emergency department with several days of visual disturbance. Her medical history included alcoholic liver cirrhosis with portosystemic encephalopathy (PSE), chronic hyponatremia, and chronic pain on opioids. She had a recent hospitalization for hepatic encephalopathy, but presented now with 5 days of new visual disturbance described mostly as an inability to see and impaired ability to focus. The patient's husband corroborated that this episode was different from her past episodes of PSE and noted that she seemed unable to attend to him during their conversations and he wondered if she was looking at things that were not present. Typically her PSE episodes were characterized by lethargy, confusion, and disorientation, whereas now she was alert, oriented to herself and recognized familiar people, and was able to have a conversation despite her visual complaints.

The patient also endorsed a holocephalic, dull headache. She had been abstinent from alcohol for 9 months and denied any substance abuse. She was compliant with her PSE regimen of lactulose and rifaximin, and reported 3-4 bowel movements daily. She requires weekly largevolume paracentesis procedures for ascites. Ophthalmology consultation was obtained and revealed no clear etiology for her visual complaints, but neurologic consultation was recommended.

\section{Questions for consideration:}

1. What is your differential diagnosis of this case of visual disturbance in a patient with decompensated liver cirrhosis?

2. How will you focus your physical examination to narrow your differential?

GO TO SECTION 2 


\section{Section 2}

A presentation of visual disturbance and inattention evokes a broad differential diagnosis, especially in a patient with cirrhosis. We considered hepatic encephalopathy, metabolic disturbances such as electrolyte or acid-base abnormalities, drug toxicity (e.g., cyclosporine or tacrolimus associated with posterior reversible encephalopathy syndrome, or anticholinergics causing sedation along with blurred version and difficulty with accommodation), encephalitis, and psychosis.

Examination revealed normal vital signs, ascites, and pitting edema in the bilateral lower extremities. The patient was oriented to person and place, but not to month or year. She exhibited horizontal nystagmus in all directions including on primary gaze. She blinked to threat reliably bilaterally, had normal optokinetic response, and her pupils were equal and reactive to light bilaterally. She had marked oculomotor apraxia and thus could not track an object through her visual field. She could not visually fixate and thus had difficulty naming objects in her visual field. She was unable to describe all parts of a picture presented and could not describe her visual field as a whole. On coordination testing, the patient was unable to target the examiner's finger with eyes open, and would misreach for objects in the entire visual field. There was slight asterixis of the bilateral upper extremities.

\section{Questions for consideration:}

1. This patient's history and examination is compatible with what classic neurologic syndrome? Where does this localize?

2. What laboratory and radiographic studies will you order to focus your differential?

3. What are some potential etiologies of this syndrome given the acute time course?

\section{GO TO SECTION 3}




\section{Section 3}

Laboratory testing revealed a sodium level of $125 \mathrm{mEq} / \mathrm{L}$. A CT scan of the head without contrast revealed no abnormalities. MRI of the brain with contrast demonstrated bilateral parieto-occipital cortical T2 hyperintensities limited mostly to the cortical gray matter with diffusion restriction in the same distribution (figure). No mass, infarction, or abnormal enhancement was seen. Continuous video EEG revealed fast oscillating right occipital activity, which would then slow to a slower spike-and-wave pattern with some anterior spread. This was often followed by fast left occipital activity, which slowed to spike-and-wave. The pattern was consistent with electrographic status epilepticus. On video, the patient was actively symptomatic throughout this period, with intermittent eye deviation and episodes of diminished attention to questioning, and at times speaking and endorsing visual hallucinations. Convulsive seizures, focal-motor manifestations, or other discreet episodic ictal events were never witnessed throughout the hospitalization.

The patient was given IV lorazepam, which initially resolved the symptoms and electrographic seizures. However, she continued to have refractory electrographic seizures on EEG and required treatment with levetiracetam, lacosamide, and phenytoin. Clinical and electrographic seizures ultimately resolved, and phenytoin was successfully tapered off over several days. Over the ensuing days of her hospitalization, her visual symptoms improved. She was discharged home at her baseline mental status on levetiracetam and lacosamide.

\section{Question for consideration:}

1. What is your final formulation and diagnosis?
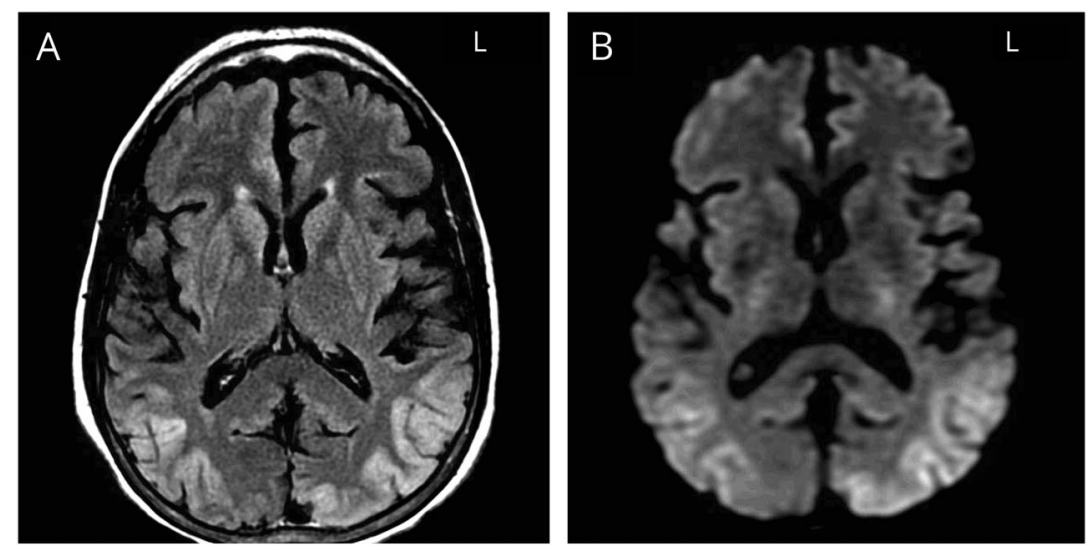

(A) Axial T2-weighted fluid-attenuated inversion recovery sequence shows bilateral parieto-occipital cortical hyperintensities limited mostly to the cortical gray matter. (B) Diffusion-weighted imaging sequence shows mild diffusion restriction in the same distribution. 


\section{Section 4}

The examination findings included oculomotor apraxia, simultanagnosia, and optic ataxia without the gross global alteration of mental status seen typically with PSE. MRI revealed bilateral parieto-occipital cortical T2 hyperintensities, which prompted EEG, revealing focal occipital status epilepticus. Taken together, these findings are most consistent with Bálint syndrome caused by focal nonconvulsive status epilepticus.

\section{Discussion}

We describe a case of Bálint syndrome as a result of bilateral occipital nonconvulsive status epilepticus. The patient's history of recurrent PSE and opioid use led to initial diagnostic confusion and due to the nature of her complaints, ophthalmology was called for consultation before a neurologic syndrome was identified. Bálint syndrome secondary to nonconvulsive status epilepticus (NCSE) has rarely been reported in the past, and never before in the setting of alcoholic cirrhosis with PSE. ${ }^{1}$ EEG in this case showed frequent alternating left- and right-sided "ping-pong" seizures in the occipital lobes and the T2 bilateral parieto-occipital hyperintensities and diffusion restriction on MRI were most likely due to this continuous seizure activity.

Bálint ${ }^{2}$ syndrome was first reported in 1909 as a bilateral parietal syndrome causing a triad of oculomotor apraxia, simultanagnosia, and optic ataxia. Of these, simultanagnosia may be the most specific and can be thought of as an extreme form of competition between objects in the visual fields. ${ }^{3}$ Optic ataxia is a high-order deficit in reaching to visual goals. A common finding would be misreaching for objects in the field contralateral to the lesion (or the entire field if both hemispheres are affected), but it can also include motor tasks such as difficulty preshaping the hand for grasping. Oculomotor apraxia refers to deficits in controlled, voluntary, and purposeful eye movements. ${ }^{2}$ While it seems clear that Bálint syndrome localizes to the posterior parieto-occipital cortex, a 2016 imaging case study of Bálint syndrome due to hemorrhage used magnetic resonance diffusion tensor tractography to demonstrate bilateral injury of the superior longitudinal fasciculus, and this was proposed as the mechanism of the syndrome in the authors' patient. ${ }^{4}$

In our case, the patient fulfilled the entire constellation of symptoms but given her repeated history of PSE there was initial concern for hepatic encephalopathy. While studies of Bálint syndrome have implicated the parieto-occipital cortex as the location of neural substrates for attention, perception, and visuomotor control including reach and grasp, ${ }^{5}$ the underlying etiology of the syndrome is varied; it can be caused by bilateral watershed infarcts in the middle cerebral artery-posterior cerebral artery distribution, bilateral parieto-occipital mass lesions, and less commonly neurodegenerative processes such as Alzheimer disease. Posterior reversible encephalopathy syndrome (PRES) was considered in this case, but the patient had normal blood pressure, was not taking any medications classically associated with PRES, and her radiographic abnormalities were largely cortical. Seizure is a relatively rare etiology of Bálint syndrome. ${ }^{1}$

While not part of the classic triad, confusion or altered mental status is also frequently reported in Bálint syndrome, which is most likely secondary to visual-spatial disorientation. The syndrome is associated with a wide variety of behavioral disturbances, which may confound the interpretation of a patient's focal deficits, and possibly overshadow the classic triad. ${ }^{6}$ These associated behavioral disturbances are likely caused by severe impairment of visual-spatial working memory, which influences a patient's inability to properly execute movements and behaviors associated with daily living. ${ }^{7}$

Another unusual part of this case is the etiology of the patient's seizures. While seizures and NCSE are somewhat uncommon in hepatic encephalopathy, they can occur, often with no overt precipitating factors leading to the patient's ultimate diagnosis of NCSE. ${ }^{8,9}$ In this case, the patient's seizures may have been related to the toxic and metabolic abnormalities associated with decompensated liver cirrhosis or simply due to hyponatremia. While her sodium level was not profoundly low, absolute sodium level is not a good predictor of whether a patient will be symptomatic, and even mild hyponatremia can cause seizures and coma if it develops rapidly. ${ }^{10}$ It is possible that Bálint syndrome is more common in NCSE, as well as NCSE being more common in hepatic encephalopathy. This case revealed a rare and fascinating neurologic syndrome with a completely reversible etiology.

\section{Author contributions}

Kyle C. Rossi cared for the patient, conceived of the case report, and wrote the manuscript. Rachel Brandstadter cared for and diagnosed the patient, conceived of the case report, and co-wrote the manuscript. Madeline Fields interpreted the EEG and critically reviewed the manuscript. Jennifer Leong critically reviewed the manuscript from liver medicine perspective. Susan Shin critically reviewed the manuscript.

\section{Study funding}

No targeted funding reported.

\section{Disclosure}

The authors report no disclosures relevant to the manuscript. Go to Neurology.org/ $\mathrm{N}$ for full disclosures.

\section{References}

1. Ristić AJ, Marjanović I, Brajković L, et al. Bálint-like syndrome as an unusual representation of non-convulsive status epilepticus. Epileptic Disord 2012;14:80-84.

2. Bálint R. Seelenlähmung des "Schauens," optische Ataxie, räumliche Störung de Aufmerksamkeit. Monatschr Psychiat Neurol 1909;25:51-81. 
3. Jackson GM, Swainson R, Mort D, Husain M, Jackson SR. Attention, competition, and the parietal lobes: insights from Balint's syndrome. Psychol Res 2009;73 263-270.

4. Jang SH, Chang CH, Jung YJ, Seo JP. Bilateral injury of the superior longitudinal fasciculus in a patient with Balint syndrome. Neurology 2016;87:1519-1520.

5. Rizzo M, Vecera S. Psychoanatomical substrates of Bálint's syndrome. J Neurol Neurosurg Psychiatry 2002;72:162-178.

6. Rizzo M. "Bálint's syndrome" and associated visuospatial disorders. Baillieres Clin Neurol 1993;2:415-437.
7. Funayama M, Nakagawa Y, Sunagawa K. Visuospatial working memory is severely impaired in Bálint syndrome patients. Cortex 2015;69:255-264

8. Jhun P, Kim H. Nonconvulsive status epilepticus in hepatic encephalopathy. West J Emerg Med 2011;12:372-374.

9. Tanaka H, Ueda H, Kida Y, Hamagami H, Tsuji T, Ichinose M. Hepatic encephalopathy with status epileptics: a case report. World J Gastroenterol 2006;12: 1793-1794.

10. Espay AJ. Neurologic complications of electrolyte disturbances and acid-base balance. Handbook Clin Neurol 2014;119:365-382.

\section{Subspecialty Alerts by E-mail!}

Customize your online journal experience by signing up for e-mail alerts related to your subspecialty or area of interest. Access this free service by clicking on the "My Alerts" link on the home page. An extensive list of subspecialties, methods, and study design choices will be available for you to choose from—allowing you priority alerts to cutting-edge research in your field!

\section{Share Your Artistic Expressions in Neurology 'Visions'}

AAN members are urged to submit medically or scientifically related artistic images, such as photographs, photomicrographs,

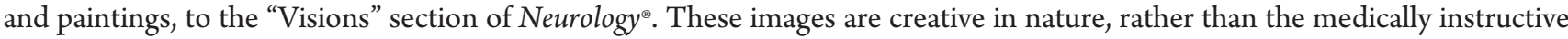
images published in the NeuroImages section. The image or series of up to six images may be black and white or color and must fit into one published journal page. Accompanying description should be 100 words or less; the title should be a maximum of 96 characters including spaces and punctuation.

Please access the Author Center at NPub.org/authors for full submission information.

\section{Disputes \& Debates: Rapid online correspondence}

The editors encourage comments on recent articles through Disputes \& Debates:

Access an article at Neurology.org/N and click on "COMMENT" beneath the article header. Responses will be posted within 3 business days.

Before submitting a comment to Disputes \& Debates, remember the following:

- Disputes \& Debates is restricted to comments about studies published in Neurology within the last eight weeks

- Read previously posted comments; redundant comments will not be posted

- Your submission must be 200 words or less and have a maximum of five references; reference one must be the article on which you are commenting

- You can include a maximum of five authors (including yourself) 


\section{Neurology}

Clinical Reasoning: A 54-year-old woman with confusion and visual disturbances Kyle C. Rossi, Rachel Brandstadter, Madeline C. Fields, et al. Neurology 2018;91;363-367

DOI 10.1212/WNL.0000000000006045

This information is current as of August 20, 2018

\section{Updated Information \&} Services

\section{References}

Citations

Subspecialty Collections

Permissions \& Licensing

Reprints including high resolution figures, can be found at: http://n.neurology.org/content/91/8/363.full

This article cites 10 articles, 2 of which you can access for free at: http://n.neurology.org/content/91/8/363.full\#ref-list-1

This article has been cited by 2 HighWire-hosted articles: http://n.neurology.org/content/91/8/363.full\#\#otherarticles

This article, along with others on similar topics, appears in the following collection(s):

All Medical/Systemic disease

http://n.neurology.org/cgi/collection/all_medical_systemic_disease

All Neuro-ophthalmology

http://n.neurology.org/cgi/collection/all_neuroophthalmology

Clinical neurology examination

http://n.neurology.org/cgi/collection/clinical_neurology_examination Status epilepticus

http://n.neurology.org/cgi/collection/status_epilepticus

Visual processing

http://n.neurology.org/cgi/collection/visual_processing

Information about reproducing this article in parts (figures,tables) or in its entirety can be found online at:

http://www.neurology.org/about/about_the_journal\#permissions

Information about ordering reprints can be found online:

http://n.neurology.org/subscribers/advertise

Neurology ${ }^{\circledR}$ is the official journal of the American Academy of Neurology. Published continuously since 1951, it is now a weekly with 48 issues per year. Copyright (C) 2018 American Academy of Neurology. All rights reserved. Print ISSN: 0028-3878. Online ISSN: 1526-632X.

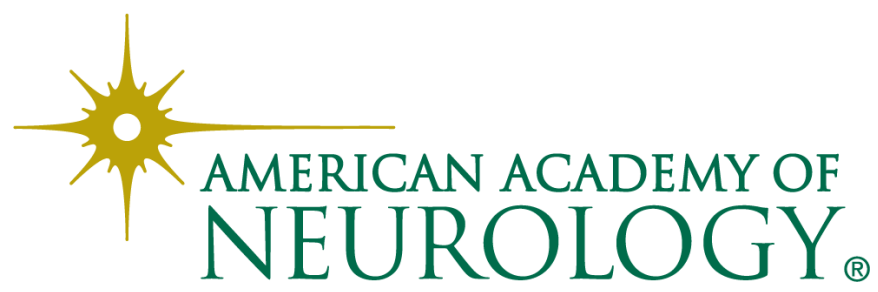

